\title{
Reflexiones sobre el régimen local inglés
}

\author{
Gonzalo Villarino Samalea \\ Departamento de Derecho Administrativo. \\ Universidad de Oviedo
}

Sumario: I. INTRODUCCIÓN. II. EL GOBIERNO LOCAL COMO STATUTORY BODY. LA DOCTRINA DEL ULTRA VIRES. III. ESTRUCTURA Y FUNCIONES. IV. LA POTESTAD REGLAMENTARIA. V. EL CONTROL DE LA ACTUACIÓN LOCAL POR EL GOBIERNO CENTRAL. VI. BIBLIOGRAFÍA.

\section{INTRODUCCIÓN}

El estudio de cuál sea la posición y funciones del Gobierno local en el Reino Unido ${ }^{1}$ constituye una tarea que reviste especial complejidad. Esto es así, porque la realización de un análisis sobre dicha materia desde una perspectiva legal -que es la que aquí se pretende- choca con la idea de que el gobierno, y muy especialmente el británico, es un concepto transido por la Ciencia política, no siempre fácilmente acomodable a parámetros jurídicos ${ }^{2}$.

De esta idea principal se derivan importantes consecuencias. La primera de ellas es la relativa a la autonomía de las Corporaciones locales. El Estado moderno inglés se caracterizó por la concurrencia de dos importantes tendencias: la distribución de funciones y una creciente centralización (a partir del gobierno conservador), ambas desafiantes de la idea del Gobierno local como institución que goza de autonomía. Este riesgo se acentúa todavía más en un país como el Reino Unido donde no existe una garantía institucional de la autonomía local al

1 En realidad, bajo esta denominación nos estamos refiriendo a Inglaterra y Gales, toda vez que el sistema legal escocés - como eslabón entre los ordenamientos del Civil Law System y los del Common Law System - cuenta con su propio régimen de administración local y que el sistema de Irlanda del Norte presenta ciertas modulaciones para aquella especifica región.

2 Esta dificultad es especialmente palmaria en el Derecho inglés donde las relaciones entre la Administración local y el Gobierno central responden la mayor parte de las veces a tensiones politicas. El Derecho público en Gran Bretaña dista mucho de constituir un cuerpo hermético o férreo que agote y regule todos y cada uno de los aspectos del ejercicio del poder. Al contrario, el armazón jurídico queda reducido a la mínima expresión, y muchos «flecos» quedan en manos de los Secretary of State a quienes se les apodera de enormes facultades que ejercerán a tenor del color político del Gobierno del que forman parte. 
estilo de la construcción germánica, y donde se acepta sin reservas que los poderes del gobiemo local proceden del Estado Central.

Por otro lado, a diferencia de lo ocurrido en los países continentales, no han sido muchas las creaciones doctrinales que se han levantado en torno al Gobierno local en Inglaterra. La razón es que desde el siglo pasado las autoridades locales han asumido importantes tareas de gobierno por lo que su valor como institución era incuestionable ${ }^{3}$. El gobierno local es esencial e insustituible porque el Estado, -excepto aquellos que no tienen ninguna pretensión de grandeza - no puede desarrollar todas las funciones por sí mismo, sino que necesita del apoyo de otras instituciones. Además, el gobierno local constituye un elemento democratizador del sistema y de pluralismo político que actúa como contrapeso al riesgo de tiranía que podría suponer un Estado excesivamente centralizado.

Pues bien, sobre estas premisas las posturas en torno a la esencia del gobierno local se han bipolarizado: a) cierto sector doctrinal to ha querido identificar como una agencia del poder central. Esta construcción cuenta con un fundamento legal indiscutible ya que, jurídicamente, las autoridades locales son corporaciones que dependen de los poderes que el gobierno central les atribuye a través de un statute; b) otro sector doctrinal entiende, en cambio, que si bien es cierta la esencia de aquella construcción de corte funcional, no lo es menos que las autoridades locales cuentan con una gran iniciativa. Para estos autores, el Gobierno local está integrado más que por deberes por poderes, y muchos de éstos se reconocen en unos términos tan amplios que les permiten usar de ellos con gran discrecionalidad. Esta corriente autonomista realza el hecho de que la innovación proviene más del nivel local que del central y de que la autoridad local se configura como una organización general con responsabilidad en múltiples funciones, que cuenta con potestad tributaria, que dentro de su ámbito de actuación dispone de una capacidad de elección que trasciende de la pura administración de tareas específicas y, por último, que tiene legitimidad política en cuanto órgano elegido democráticamente.

Con todo, lo cierto es que la autonomía que pueda predicarse de las local authorities inglesas no puede parangonarse a la autonomía de que gozan en España. Aquéllas se encuentran firmemente encorsetadas, ejercen sus potestades por medio de legislación delegada (no originaria), y no cuentan con un cuerpo legal que establezca sus responsabilidades mínimas sino que se hallan sujetas a

3 El enfoque tradicional sobre la Administracion local inglesa sugiere bien a las claras que si las instituciones de Gobierno local son tan antiguas como el Gobierno central habrán de contar con su propia justificación. Como vemos, el sentido del pragmatismo no puede ser más elevado. 
los designios del gobierno central, el cual puede a capricho modificar por completo su status ${ }^{4}$.

Sobre esta base no es de extrañar que la organización, gestión y estructura de las Administraciones locales se encuentre en permanente cambio y análisis crítico de sus funciones. Por ello, en este trabajo no pretendemos únicamente exponer las líneas maestras de actuación de tales autoridades sino también los vaivenes y sentires políticos que actualmente influyen en la definición de la actuación municipal.

\section{EL GOBIERNO LOCAL COMO STATUTORY BODY. LA DOCTRINA DEL ULTRA VIRES}

La Local Government Act de 1972, norma básica en materia de régimen local, establece en sus secciones 2 y 21 que todos los Counties y District Conncils de Inglaterra y Gales tendrán la consideración de Corporaciones. Lo mismo disponen las secciones 14 y 33 para las parishes inglesas y las communities galesas, respectivamente.

Según las reglas del Common Law, solamente la Corona, - bajo sanción del Parlamento- puede conferir a un ente este status artificial ${ }^{5}$. Con ello no se quiere enfatizar la multiplicidad de personas que componen la Corporación sino más bien su capacidad. Este dato es el que permite distinguir en Derecho inglés las corporation aggregate de las corporation sole. Las primeras están constituidas por varias personas fisicas tratadas artificialmente como una sola persona en el desempeño de sus funciones para lograr el interés público. Las segundas, en cambio, aluden a una única persona física tratada como si fuera persona jurídica ${ }^{6 \mathrm{y}}$ ?

En este estado de cosas resulta clara la necesidad de decidir qué decisiones tomadas por una persona física ya sea por sí misma o como parte de un corpo-

\footnotetext{
4 Estas modificaciones en cuestión se han producido no sólo periódica sino también repetidamente en los últimos af́os. Véanse las Local Government Act de 1985, 1986, 1990, 1992... Y actualmente existe una reforma pendiente $\mathrm{ca}$ Westminster.

5 Hablando incidentalmente del municipio de Cambridge, F. W. Martzand escribió en su ensayo "Township and borough" que la invención de una personalidad ficticia es una "hazaña de habilidad, un ingenioso artificio de jurisprudencias. Vid. Selected Essays of $F$. W. Maitland, edit. H. M. Cam, Beacon Press and CUP, 1962, pág. 11.

6 Ha sido el Derecho canónico el que ha utilizado estos conceptos y de aqui pasaría al Common Law medieval.

7 Quizás los ejemplos más ilustrativos de estas últimas sean los Ministers y el Monarca.
} 
rate aggregate se imputan por la Ley a las personas jurídicas de las que aquéllas forman parte. De ahí que el principio más importante en relación con el corporate status sea la doctrina del ultra vires.

Esta doctrina que se acuñó en la alocución de Lord Watson en el caso Baroness Wenlock v. River Dee Co. ${ }^{8}$ viene a señalar que, así como una persona física puede hacer todo aquello que le parezca en tanto en cuanto no esté prohibido o sea contrario a Derecho, una statutary corporation sólo puede hacer aquello que le permita el statute y en caso contrario incurriría en ultra vires. Ahora bien, la estricta aplicación de esta regla obstaculizaría gravemente las posibilidades de actuación de las Corporaciones locales. Por ello, los Tribunales ingleses han sostenido que tales Corporaciones pueden hacer no sólo aquellas cosas para las que están expresa o tácitamente autorizadas sino también para lo que es razonablemente incidental ${ }^{9}$.

Esta regla de Common Law ganó fuerza escrita al ser recogida en la sección 111 de la Local Government Act de 1972 («Authorities are empowered to do anything which is calculated to facilitate, or is conductive or incidental ${ }^{10}$ to, the discharge of any of their functions')). Asi pues, los supuestos en que se permite la actuación de las autoridades locales son aquellos en que: a) exista específica autorización en el statute; b) dicha autorización se deduzca implícitamente; c) el acto a realizar se considere razonablemente incidental para llevar a cabo los propósitos contemplados en el statute. Ni que decir tiene que los casos que más han motivado la intervención de los tribunales son los dos últimos, pero su estudio no lo haremos aquí, sino al abordar el control judicial de la intervención local.

La doctrina del ultra vires no se aplica únicamente a las cuestiones materiales o de fondo. Al contrario, el Parlamento puede exigir por medio de statute que las decisiones se adopten siguiendo un procedimiento determinado, resultando frecuente que así lo haga $"$. Alternativamente, los Ministros pueden tener

8 El párrafo de la sentencia decía literalmente: "Whenever a corporation is created by Act of Parlament with reference to the purposes of the Act, and solely with a view to carrying these purposes into execution, I am of opinion not only that the objects which the corporation may legitimately pursue must be ascertained from the Act itself, but that the powers which the corporation may lawfully use in furtherance of these objects must either be expressly conferred or derived by reasonable implication from its provisions). Ref. 188510 App. Cas. 354, pág. 362.

9 Véase Lord Selborne en el caso Att.-Gen. v. Great Eastern Ry. Ref. 18805 App. Cas 473, pág. 478.

10 La expresión «incidental» no es equivalente a uen conexión con» sino que tiene un significado más restringido. Vid. Amalgamated Society of Railway Servants v. Osborne. Ref. [1910] A.C. 87, pág. 97.

11 La mayor parte de los casos de ultra vires se refieren a si un proyecto se puede acometer legalmente. No obstante, la doctrina de ultra vires también se puede invocar como control de los medios empleados para alcanzar aquellos proyectos, tal y como ha señalado la House of Lords. Por su parte, los Tri- 
poderes para eliminar tales exigencias procedimentales. Ahora bien, queremos adelantar ya - con el fin de evitar equívocos- que el incumplimiento del deber de seguir un procedimiento determinado sólo conduce al ultra vires cuando se trata de una medida imperativa (mandatory or imperative) y no cuando es potestativa (directory). Existen muchos casos en los que se puede apreciar la diferente naturaleza de unas y otras. Sin embargo, los Tribunales no han llegado a establecer claras directrices de cuándo las normas son mandatory or directory. Con todo, podemos deducir de sus pronunciamientos que son imperativos aquellos requirements que se refieren al ejercicio de derechos, imposición de obligaciones, salvaguardia de intereses privados y derecho a formular alegaciones.

Los particulares que acudan a los Tribunales a raíz de un pretendido statutory ultra vires o porque las autoridades locales no actuaron en tiempo deben hacerlo en un plazo de seis semanas desde que la última orden o decisión fue tomada. La apreciación por aquéllos de una violación al principio que estudiamos acarrea dos importantes consecuencias: primero, los procedimientos legales deben ser comenzados en la High Court; segundo, el Alto Tribunal puede otorgar una o varias acciones, ya propias del Derecho público (prerrogative orders of certiorari, prohibition y mandamus) ya propias del Derecho privado (injunction, declaration, y damages) ${ }^{12}$. En suma, advertida una vulneración del ultra vires, la High Court puede:

\section{- Impugnar la decisión (certiorari)}

- Prohibir una acción ultra vires que eventualmente pudiera ejecutarse (prohibition, injunction)

- Imponer el cumplimiento de un deber público (mandamus, injunction)

- O simplemente clarificar la situación legal (declaration)

bunales han establecido igualmente que existe exceso en el poder cuando éste se ejercita de mala fe o para fines impropios, cuando se ignoran relevantes consideraciones legales o cuando se atiende a las irrelevantes, y también cuando la decisión adoptada es tan poco razonable que ninguna autoridad actuaria de ese modo.

12 Nótese que las primeras son las que prevé la Order 53 de las reglas de la Corte Suprema. Las segundas, en cambio, pueden ser vistas en procedimientos normales de la Corte, aunque en la práctica tales acciones se ejercitan también por los cauces de la orden 53 si el caso que se enjuicia cae dentro del ámbito general de la misma. 


\section{ESTRUCTURA Y FUNCIONES}

El armazón legal imperante en Inglaterra y Gales en materia de régimen local es el que estableció la Local Government Act (1972), cuya entrada en vigor tuvo lugar el 1 de abril de $1974{ }^{13}$.

La $L G A$ no sólo establece el nuevo sistema de áreas y autoridades sino que deroga la $A c t$ de 1933 en el que se contenían las principales disposiciones sobre procedimiento electoral, financiación y funciones de las autoridades locales ${ }^{14}$. Se trata de una Ley amplia, con 30 apéndices que se complementa con la $L G A$ (1974) que aborda las cuestiones relativas a tributos, finanzas y recursos judiciales contra el gobierno local.

A partir de 1974 tanto Inglaterra como Gales se estructuran en Counties y Districts. En la primera se establecieron 6 metropolitan Counties (Greater Manchester, Merseyside, West Midlands, West Yorkshire, South Yorkshire, Tyne and Wear) divididos en 36 metropolitan districts y 39 Counties no metropolitanos divididos en 296 districts. Los conncils metropolitanos fueron abolidos posteriormente, en 1986 en virtud del LGA de 1985 y sus funciones repartidas entre los distritos metropolitanos y un número determinado de joint authorities creadas para asumir funciones específicas. En la segunda, se establecieron 8 Counties no metropolitanos divididos en 37 districts. Los distritos ingleses se definen por Order, los galeses, en cambio, ya aparecen enumerados en la Act (vid. 4. ${ }^{\mathrm{a}}$ schedule, pt. II).

Los County Councils están integrados por el chairman y los councillors democráticamente elegidos por un período de cuatro años. Todos ellos cesan de su cargo al mismo tiempo. Cada council cuenta con una serie de competencias que puede ejercer en concurrencia con los districts tales como museos y galerías de arte, terrenos abandonados, parques y jardines, baños públicos, ocio y deportes, aeropuertos, conservación de árboles, y otros muchos aspectos de desarrollo urbano. Otras competencias, en cambio, le corresponden en exclusiva: planificación a nivel del county, autopistas, protección a los consumidores, educación, empleo juvenil, etc.

\footnotetext{
13 En esta misma fecha entraron en vigor la reorganización del National Health Service y el funcionamiento de las Water Authorities, por lo que nos encontramos ante un verdadero hito en la historia del Derecho administrativo.

14 Este cuerpo legal viene a ejecutar las propuestas contenidas en el Libro Blanco «El Gobierno local en Inglaterra: propuestas gubernamentales para su reorganización» y en el documento consultivo «La reforma del Gobiemo local en Gales" publicado en 1971.
} 
Cada County Council está dividido en una serie de Districts cada cual cuenta con su correspondiente Council integrado igualmente por un chairman y varios councillors. Cada miembro es elegido para un período de cuatro años, pero normalmente una tercera parte del council se renueva cada año, excepto en aquellos años en que se han de celebrar elecciones. Con todo, han sido muchos los councils que han optado por la permanencia de todos sus miembros durante la totalidad del mandato. Así como las funciones compartidas con los Counties, los districts council asumen competencias exclusivas en materias como vivienda, regulación sobre edificios, ferias y mercados, salud pública, licencias locales, recogida de residuos, seguridad en el hogar, planificación urbana, etc.

Junto con los tipos de autoridad local ya señalados existen otros de menor importancia. Entre ellos se encuentran las parishes y las communities. Cada parish (equiparable a nuestra parroquia rural) debe tener un parish meeting. Con carácter general una parroquia pequeña puede tener un parish conncil si lo desea; en cambio, las parroquias grandes están obligadas a tenerlo. Tanto las parroquias grandes como las pequeñas pueden agruparse bajo un mismo órgano rector si así lo desean. Las reglas son las siguientes: el district council debe establecer obligatoriamente una parish council si la parroquia cuenta con 200 o más electores o si cuenta entre 150 y 200 y la parroquia lo quiere. En las parroquias con menos de 150 electores, el district council goza de discrecionalidad para crearla o no.

En Gales, los Districts se dividen en communities. Todas las parishes existentes se convirtieron automáticamente en communities el 1 de abril de 1974. Pero con anterioridad a esta fecha un municipio ya existente o urban district council podía solicitar la creación de un community council para su área estando obligado el Ministro a concederlo. Los district councils vienen obligados a establecer un community council si el community meeting así lo dispone. La misma regla se aplica para los casos de disolución.

De este régimen general de división territorial se exceptúa el gobierno de la ciudad de Londres. La revisión del gobierno en Londres capital tuvo lugar una década antes que en el resto del país, con la London Government Act (1963) que fue precedido de un informe de la Royal Commission. Esta Act derogó el London County Council que había sido creado en 1888 y los municipios metropolitanos de 1899 y creó en su lugar el Greater London Council. Éste, en cambio, fue abolido por la Local Government Act (1985) de modo que, muy resumidamente y sin ánimo de ofrecer un estudio de sus funciones, podemos afirmar que, hoy en día, los órganos llamados a desarrollar el gobierno de la enorme capital son: a) los 32 London boroughs, b) la Corporación de la City de Londres, c) the Temples (Inner Temple y Middle Temple) y d) un abundante número de autoridades creadas para ejercer funciones ad hoc (the London Fire 
and Civil Defence Authority, the London Residuary Body, the London Pensions Fund Authority, the London Regional Transport, etc.).

En definitiva, a pesar de las leves diferencias que puedan presentar los distintos cuerpos de autoridades locales, todos ellos mantienen unas caracteristicas comunes que los diferencian del funcionamiento del Gobierno central. Tales características son: a) no existe separación de poderes, los Council son tanto órganos ejecutivos como normativos, aunque sus funciones normadoras se limiten a la potestad reglamentaria para el buen gobierno y supresión de molestias; b) los poderes de las autoridades locales son exclusivamente estatutarios. En cambio, el gobierno central cuenta también con poderes derivados del Common Law; c) los funcionarios locales son empleados de la autoridad a la que están unidos por una relación contractual. Las dudas que pueden surgir acerca del status de los funcionarios del Estado (Civil Service) no son predicables aquí. Sin embargo, algunos funcionarios locales pueden ser designados en un statute con competencias y responsabilidades propias en cuyo caso no actuarán en nombre de la autoridad y, por tanto, ésta no será legalmente responsable de los errores que puedan cometer, a menos que el statute así lo declare expresamente; y d) las autoridades locales pueden delegar sus funciones en comités, sub-comités o unir comités con otras autoridades locales. En la práctica, la mayor parte de las funciones se delegan en comités. Funcionarios y concejales de todos los partidos políticos participan en comités manteniendo entre sí una relación muy similar a la que mantiene, dentro de una compañía, el personal ejecutivo con el no ejecutivo. Se trata, por tanto, de una relación muy parecida a la sostenida entre Ministers y civil servants.

\section{LA POTESTAD REGLAMENTARIA}

La potestad reglamentaria de las autoridades locales en el Reino Unido deriva siempre del statute. No es posible hablar de una potestad reglamentaria originaria que como en España desprenda su legitimidad directamente de la Constitución, por la sencilla razón de que en el Reino Unido no existe una Constitución escrita. Existe, eso sí, una doctrina según la cual los Corporate Bodies tienen un poder normador inherente, pero parece dudoso que dicha construcción pueda ir tan lejos como para englobar a las Corporaciones locales. Por otro lado, es cosa probada que estos entes no confian en absoluto en las potestades que pueda atribuirles el derecho del Common Law.

El poder de dictar reglamentos debe venir por tanto establecido en el statute. $\mathrm{Al}$ respecto hemos de sefialar que existe un apoderamiento general contenido en la sección 235 de la $L G A 1972$, la cual permite a las autoridades locales dic- 
tar ordenanzas para el buen gobierno y la eliminación de molestias. La amplitud de esta sección es clara y abre la puerta a buen número de ordenanzas (bylaws, según la terminología anglosajona) ${ }^{15}$.

El procedimiento general para dictar ordenanzas es el contenido en la sección 236 de la $L G A$ 1972. Este procedimiento se utiliza para todas aquellas ordenanzas que tengan como cobertura la mencionada Ley o para aquellas otras hechas bajo otro apoderamiento en el que sin embargo no se detalla el procedimiento a seguir. Primero, la ordenanza ha de dictarse bajo el sello del Council o bajo las manos y sellos de dos miembros en el caso de las parishes o communities councils que no dispongan de sello. Segundo, el Conncil debe publicar en al menos un periódico local su intención de dictar la ordenanza y elevarla en el plazo de un mes a la autoridad que especifica el statute que confiere el poder de dictar by-laws para su confirmación. Esta autoridad debe examinar si la ordenanza: a) es intra vires, b) si pasaría un futuro y eventual control judicial, c) si es necesaria. Con carácter general se suelen confirmar todas aquellas ordenanzas que siguen un modelo preestablecido, en cambio, no existen garantías cuando la autoridad local se aparta de ese modelo. Esta medida de presión tiene su razón de ser pues se entiende que el modelo proporciona uniformidad y seguridad. Finalmente, en caso de confirmación la autoridad señala el día en que la ordenanza entrará en vigor.

Las ordenanzas tienen fuerza vinculante, son normas que integran el ordenamiento jurídico al igual que los statutes. Existe, sin embargo, una capital diferencia entre unas y otros. Respecto de estos últimos, los Tribunales están obligados a aplicarlos tal como están. En cambio, las ordenanzas están sometidas al examen de los Tribunales, quienes han dispuesto ciertos parámetros judiciales de validez. Estos parámetros son los siguientes: a) la ordenanza debe ser razonable. Ahora bien, en tanto que dictadas por órganos representativos de los ciudadanos es opinión judicial que las ordenanzas deben ser mantenidas en todo lo posible ${ }^{16}$; b) cierta en sus términos. Los derechos y deberes de las partes han de quedar perfectamente definidos; c) consecuente con la Ley. Una ordenanza es inválida si es repugnante a la Ley o si versa sobre una materia ya agotada por la misma. No puede permitir aquello que la Ley prohíbe expresamente ni prohibir lo que expresa o tácitamente permite ${ }^{17}$. De igual modo, una ordenanza

15 Estas ordenanzas abarcan una gran cantidad de materias, tal y como se puede comprobar en el modelo fijado por el Secretary of State for the Home Department. El modelo contiene clausulas sobre las siguientes materias: música cercana a casas, iglesias, hospitales, pregones ruidosos, altavoces, lenguaje indecoroso, violencia en las escuelas, baños impúdicos, exhibicionismo, holgazanear a la puerta de las iglesias, anuncios publicitarios, banderas, escupir, ciclismo en vias públicas peatonales, animales, ...

16 Vid. Kruse v. Johnson [1898] 2 Q.B. 91, pág. 108.

17 Es cierto que en Derecho inglés los statutes no suelen declarar expresamente cuáles o tales actos es- 
puede ser judicialmente impugnada si es repugnante a algún principio básico del Common Law. Sí pueden, por ser precisamente su tarea, llevar a cabo el complemento y desarrollo de una Ley preexistente; d) intra vires. Las ordenanzas no pueden ir más allá de lo que el statute les permite.

Un aspecto interesante es el relativo a la capacidad sancionadora de los bylows. Las Ordenanzas dictadas según el procedimiento del Act de 1972 pueden imponer sanciones (normalmente pecuniarias) de cuantía no superior a la fijada en el statute. Si en éste no aparece fijada ninguna suma, el límite será el nivel segundo de la escala estándar. Se trata de una regla aplicable tanto para las ordenanzas ya existentes como para las que están por dictar. En el caso de que la infracción sea continuada en el tiempo la ordenanza puede prever multas por cada día que siga la ofensa. Cualquier persona puede denunciar el incumplimiento de ordenanzas e instar el procedimiento sancionador a menos que el statute en el que descansa la ordenanza restrinja la legitimación a determinadas personas o entes ${ }^{18}$.

Por último, queremos señalar que no cabe que una autoridad renuncie a la aplicación de sus Ordenanzas o a la relajación de sus términos ${ }^{19}$ a menos que la propia ordenanza así lo contemple, o exista previsión legal al respecto. Por otra parte, cualquier autoridad local puede revocar sus propias ordenanzas pero necesita la confirmación de la autoridad que inicialmente la ratificó.

\section{EL CONTROL DE LA ACTUACIÓN LOCAL POR EL GOBIERNO CENTRAL}

Las autoridades locales se encuentran sometidas al Gobierno central porque su existencia, financiación y poderes dependen de lo que disponga la Ley. El Parlamento es omnipotente, y puede otorgarles competencias o privarles de ellas. También puede disponer el modo en que tales competencias hayan de ser ejercitadas, así como modificar la estructura del régimen local.

\footnotetext{
tán permitidos. Pero si pueden $-\mathrm{y}$ a veces lo hacen- declarar prohibidos una serie de actos, a menos que se cumplan ciertas condiciones. En este caso sí que se puede hablar de que la Ley permite unos actos expresamente - aunque sean excepcionales- de modo tal que una ordenanza contraria al statute sería considerada ilegal.

18 Un ejemplo de este tipo de restricciones es el contenido en la s. 298 de la Public Health Act (1936) según el cual sólo una parte ofendida del Council puede proceder sin el consentimiento escrito del Fiscal General.

19 La Highways Act (1980) en su sección 190 autoriza, con el consentimiento del Secretary of State for the Environment, a que se relajen los requisitos de las Ordenanzas respecto a nuevas calles.
} 
Los Tribunales ingleses han reconocido que los órganos que componen la Administración local no son necesariamente agentes del Gobiemo central, sin embargo, han sido incapaces de formular principios directores de la relación constitucional entre ambas Administraciones, sino que se han limitado a supuestos específicos y concretos. Con todo, podemos afirmar que la intervención central sobre el Gobiemo local es deseable en la medida en que asegure un denominador común en el ejercicio de los poderes locales que permitan eludir discrepancias entre los organismos llamados a prestar servicios en ambas Administraciones y coordinar planes de actuación. Durante los últimos años hemos asistido a un considerable aumento de la litigación entre ambos niveles de gobierno, hasta el punto de que los Tribunales han llamado la atención sobre este abuso, y sobre el peligro que comporta la utilización de criterios estrictamente políticos como argumentos a hacer valer en un proceso judicial ${ }^{20}$.

Aparte de esta capital forma de control que es el poder de legislar, el gobierno central puede ejercer control sobre las autoridades locales a través de estos otros cauces:

a) La facultad de otorgar o no concesiones.

b) El control sobre los niveles que pueden alcanzar los tributos locales.

c) El control sobre los ingresos y gastos.

d) El ejercicio de poderes por los Ministros en caso de omisión por las autoridades locales. Los casos en que puede producirse dicha avocación de poder varían. En algunas ocasiones se exige un «comportamiento irracional» ${ }^{21}$; en otras, en cambio, se permite la avocación sin la concurrencia de este requisito ${ }^{2}$.

e) El veto a la actuación municipal, por ejemplo, a las ordenanzas.

f) El poder de restringir la autonomía local imponiendo estándares mínimos de actuación.

g) Inspecciones, auditorías y requerimientos.

h) Empresas mixtas entre Gobierno central y local.

20 Al respecto puede verse Nottinghamshire CC v. Secretary of State [1986] 1 All ER pág. 199.

2) Vid. Secretary of State for Education and Science v. Tameside Metropolitan Borough Council, [1977] AC, 1014.

22 Nonwich City Council v. Environmental Secretary [1982] All ER 737. 
Como se ve, el control al que las autoridades locales se ven sometidas es feroz. En este recorte del campo de actuación independiente del gobierno local, ha jugado un papel fundamental la intervención del Parlamento, sobre todo, a partir de la etapa conservadora, pues ha sido la Ley la que ha configurado a aquél como una agencia del poder central. Según esta concepción, el gobierno local se halla dentro de una relación jerárquica cuya cúspide es Westminster. Parece como si hubiese desaparecido la idea de que la democracia ejercida por los consistorios es fundamental en un Estado moderno. Ahora bien, aunque indudablemente todos estos cambios conllevan serias implicaciones, no suponen el estoque definitivo del gobierno local. Dada la complejidad del gobierno en el mundo actual resulta inconcebible que todo pueda ser dirigido desde la Administración central. Así se ha percibido en el Reino Unido, hasta el punto de que no han sido pocas las voces que, tanto desde los Municipios y Autonomías como desde el propio Parlamento, proclaman la necesidad de iniciar una nueva era en las relaciones entre ambas esferas. De este modo, el debate sobre la capacidad del gobierno local para mantener su capacidad de iniciativa e innovación no acaba, paradójicamente, más que empezar.

\section{BIBLIOGRAFÍA} 1994.

AlDER, J., Constitutional and Administrative Law, Macmillan, London,

Cross, C. and Balley, S., Cross on Local Government Law, Sweet and Maxwell, London, 1986.

J. Jowell and D. Oliver, The Changing Constitution, Clarendon Press, Oxford, 1994.

LovghuIN, M., Local Government in the Modern State, McGraw Hill, London, 1986.

McELDowney, J. F., Public Low, Sweet and Maxwell, London, 1994.

WadE, H. W. R. and Forsyth, C.F., Administrative Law, Clarendon Press, Oxford, 1994. 